\title{
Exploring endoperoxides as a new entry for the synthesis of branched azasugars
}

\author{
Svenja Domeyer, Mark Bjerregaard, Henrik Johansson and Daniel Sejer Pedersen ${ }^{*}$
}

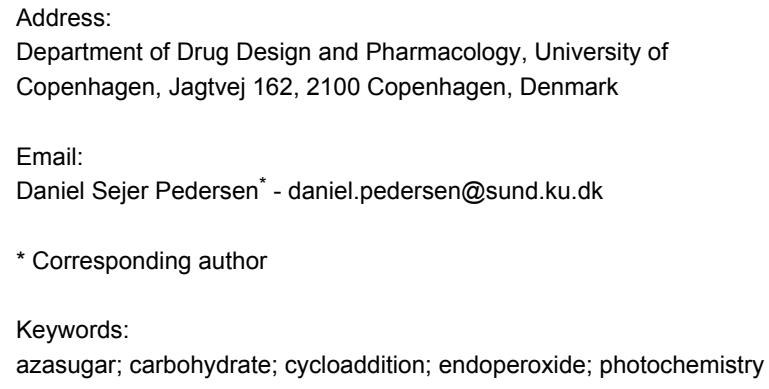

Beilstein J. Org. Chem. 2017, 13, 644-647.

doi:10.3762/bjoc. 13.63

Received: 16 December 2016

Accepted: 13 March 2017

Published: 03 April 2017

Associate Editor: S. Flitsch

(C) 2017 Domeyer et al.; licensee Beilstein-Institut.

License and terms: see end of document.

\begin{abstract}
A new class of nitrogen-containing endoperoxides were synthesised by a photochemical [4 + 2]-cycloaddition between a diene and singlet oxygen. The endoperoxides were dihydroxylated and protected to provide a series of endoperoxide building blocks for organic synthesis, with potential use as precursors for the synthesis of branched azasugars. Preliminary exploration of the chemistry of these building blocks provided access to a variety of derivatives including tetrahydrofurans, epoxides and protected aminotetraols.
\end{abstract}

\section{Introduction}

Azasugars are small organic compounds that can mimic carbohydrates or their hydrolysis transition states as well as having many other interesting properties. They are found in nature as pyrrolidines, piperidines, indolizidines, pyrrolizidines or nortropane alkaloids with a variety of ring substituents, typically hydroxy groups, carboxylic acids and amides [1]. The ability of azasugars, such as the natural product deoxynojirimycin, to inhibit the activity of a wide range of enzymes has attracted attention for their potential use as drug candidates [2,3]. Azasugars in clinical use today include Glyset, a licensed drug for treatment of diabetes type II, and Zavesca, which is used in treatment of type I Gaucher's disease and Niemann Pick type C disease (Scheme 1).
Historically, azasugars were most commonly synthesised from available carbohydrate starting materials, a strategy that is still extensively employed today [4,5]. However, a variety of alternative synthetic strategies have since been developed, including asymmetric and chemoenzymatic methods [2,6-8]. Substituted endoperoxides have been applied to the synthesis of substituted cyclopropanes, furans and carbohydrates [9-12]. Inspired by the work of Robinson and co-workers [10-12] we hypothesised that endoperoxides might provide a new entry to branched azasugars with novel stereochemistry and substitution patterns (Scheme 1). Herein we wish to report our preliminary results in synthesising nitrogen containing endoperoxides as a potential new source for the divergent synthesis of azasugars. 


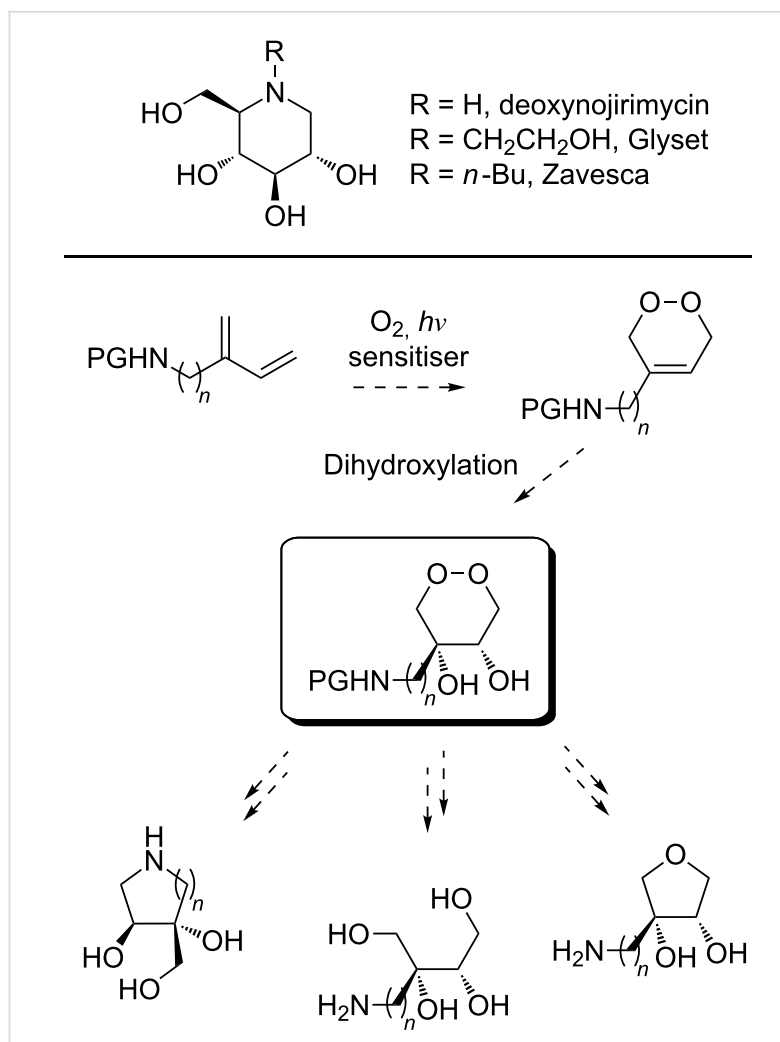

Scheme 1: Top: The natural product deoxynojirimycin and two analogues and marketed drugs Glyset and Zavesca. Bottom: Our synthetic strategy aimed to explore substituted endoperoxides

(e.g. dihydroxylated endoperoxide, box) as key intermediates for the divergent synthesis of novel azasugars. $P G=$ protection group.

\section{Results and Discussion}

We set out to synthesise two diene substrates for a photochemical $[4+2]$-cycloaddition with singlet oxygen to provide two different endoperoxides (Scheme 1, $n=1-2$ ). Based on literature precedent Boc-protection was utilised for the amino group (Scheme 2) $[13,14]$. Moreover, the phthalimide-protected compounds were synthesised as UV active analogues that would facilitate analysis.

Aminoalcohols 1 and 2 were Boc- and Pht-protected under standard conditions to provide alcohols 3-6 in good yield. Oxidation of alcohol 3 to aldehyde 7 was achieved in moderate yield using standard Parikh-Doering oxidation conditions [15]. However, when the same conditions were applied to alcohol 4 it resulted in a complex mixture. Other oxidation procedures, including TPAP [16], Dess-Martin periodinane [17] and TEMPO [18] were attempted but in all instances complex mixtures were obtained and none of the desired aldehyde $\mathbf{8}$ was observed. Presumably the problems encountered with compound $\mathbf{4}$ originates from the ability of the carbamate nitrogen to form a fivemembered hydroxypyrrolidine that can undergo further oxidation [19]. Oxidation of alcohol 5 to give aldehyde 9 was accom-

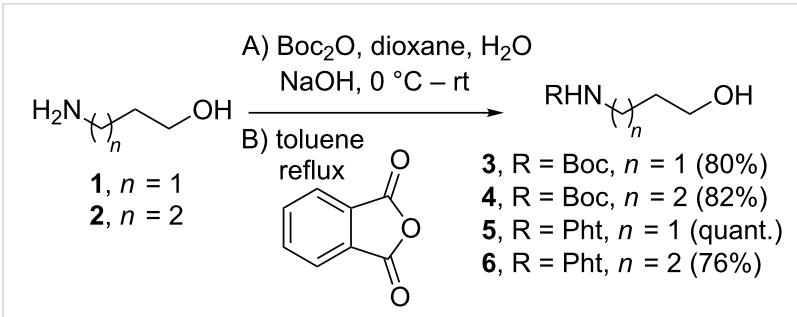

A) $\mathrm{SO}_{3} \cdot \mathrm{py}, \mathrm{Et}_{3} \mathrm{~N}$

DMSO

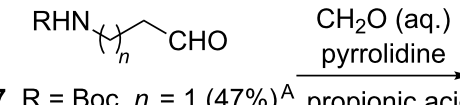

B) TEMPO, TBA-C $\mathrm{NCS}, \mathrm{NaHCO}_{3}$ $\mathrm{K}_{2} \mathrm{CO}_{3}, \mathrm{H}_{2} \mathrm{O}$ $\mathrm{CHCl}_{3}$

8, $\mathrm{R}=$ Boc, $n=2(0 \%) \quad 45^{\circ} \mathrm{C}$

9, $\mathrm{R}=\mathrm{Pht}, n=1(38 \%)^{\mathrm{B}}$

10, $\mathrm{R}=$ Pht, $n=2(83 \%)^{\mathrm{A}}$
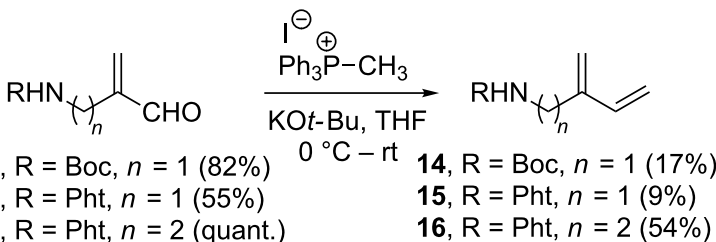

Scheme 2: Synthesis of Boc- and Pht-protected diene substrates for endoperoxide synthesis. $\mathrm{TBA}-\mathrm{Cl}=$ tetrabutylammonium chloride, $\mathrm{NCS}=\mathrm{N}$-chlorosuccinimide

plished in a low yield using TEMPO, whereas oxidation of $\mathbf{6}$ using the Parikh-Doering method gave a good yield of aldehyde 10. Next, aldehydes 7, 9 and $\mathbf{1 0}$ were subjected to a Mannich reaction using the method by Erkkilä and Pihko to give the $\alpha, \beta$-unsaturated aldehydes 11-13 in good yields [20]. The final step of the diene synthesis was a Wittig reaction with methyltriphenylphosphonium iodide to provide 14-16. Compound $\mathbf{1 4}$ was found to be volatile and thus was only isolated in a poor yield. For diene $\mathbf{1 5}$ the low yield was largely due to complications with removing the triphenylphosphine oxide side product. However, at this stage sufficient material of dienes 14-16 was available to proceed to the critical cycloaddition and dihydroxylation steps and thus no further optimisation was performed.

The cycloaddition reaction of dienes 14-16 with singlet oxygen was performed in a modified photochemical reactor that had been fitted with a gas inlet tube at the bottom to allow bubbling of oxygen through the reaction mixture whilst simultaneously cooling and irradiating (Scheme 3). During the synthesis of diene 14 we found that it was volatile and thus we anticipated problems in the cycloaddition due to the reaction set up. As anticipated when the reaction was performed with the sensitizer rose bengal the diene was observed to quickly disappear from the system and only a low yield of endoperoxide 17 was obtained. Due to the many problems encountered with the Bocprotection strategy it was abandoned at this stage and we turned our attention to the phthalimide-protected dienes $\mathbf{1 5 , 1 6}$. When 


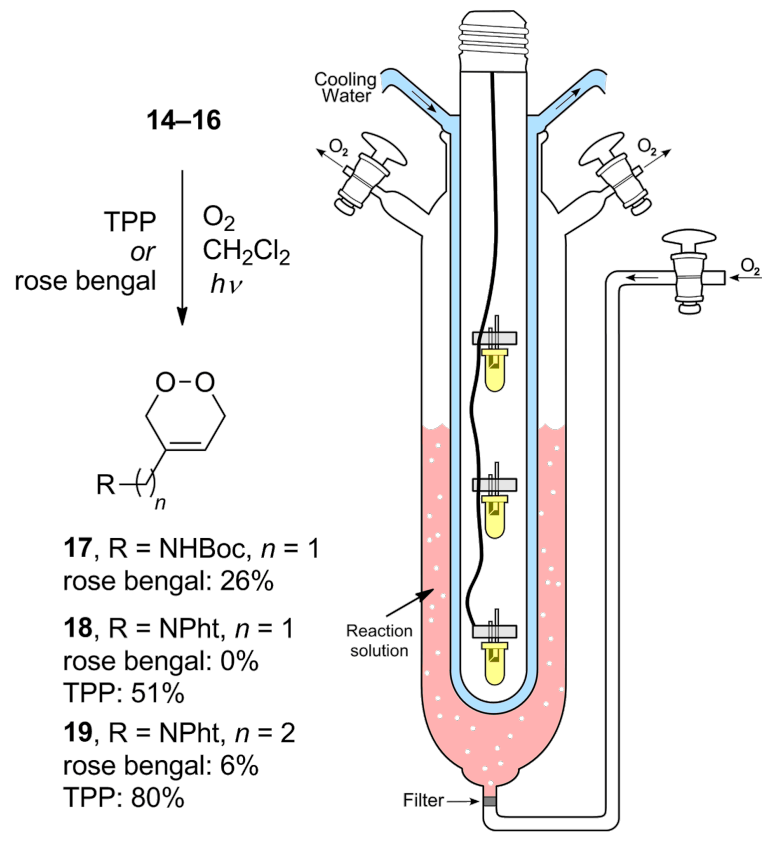

Scheme 3: Synthesis of endoperoxides 17-19 by [4 +2 -cycloaddition of dienes 14-16 with singlet oxygen. The photochemical reactor was modified with a gas inlet fitted with a filter at the bottom of the reactor, and the original mercury lamp was replaced with three $100 \mathrm{~W}$ halogen bulbs.

the same reaction was performed with rose bengal on diene 16 a very low yield of endoperoxide $\mathbf{1 9}$ was obtained and most starting material was recovered (78\%) even after prolonged reaction time $(40 \mathrm{~h})$. However, the reaction outcome was greatly improved by exchanging the sensitizer with tetraphenylporphyrin (TPP) to give a good yield of the desired endoperoxide 19. Likewise, diene $\mathbf{1 5}$ was converted to the correspond- ing endoperoxide 18 in good yield using TPP, whereas no product was obtained using rose bengal.

With endoperoxides $\mathbf{1 8}$ and $\mathbf{1 9}$ in hand the stage was set for the central dihydroxylation reaction that would give access to key intermediates 20 and 21 (Scheme 4). To our delight dihydroxylation with potassium osmate in the presence of citric acid was smooth and gave excellent yields of diols 20 and 21 [11]. Diols 20 and 21 were found to be unstable unless stored at $-20{ }^{\circ} \mathrm{C}$. However, protection of the diol moiety as an acetonide to give endoperoxides $\mathbf{2 2}$ and $\mathbf{2 3}$ rendered the compounds stable at ambient temperature. Compounds 18-23 lend themselves to undergo a wide range of chemical transformations and are therefore valuable building blocks that will allow in-depth exploration of the chemistry of this class of azasugar precursors. Some preliminary experiments were performed to assess the possibilities that these building blocks grant.

Endperoxide 19 was epoxidized under standard conditions to provide the desired epoxide $\mathbf{2 5}$ and the anti-diol $\mathbf{2 6}$ as a by-product. Likely, diol $\mathbf{2 6}$ is formed by ring-opening of the epoxide by water present in the $m$ CPBA and the reaction could be optimised by performing the reaction under anhydrous conditions. Attempts at cleaving the endoperoxide bond of $\mathbf{2 0}$ and 21 by catalytic hydrogenation resulted in rapid decomposition. However, when the same conditions were applied to acetonide-protected endoperoxide $\mathbf{2 3}$ the desired diol $\mathbf{2 8}$ was obtained, albeit in low yield, with the lactol isomers 29 and $\mathbf{3 0}$ as the major product $(45 \%)$. It is somewhat surprising that the lactols were formed under these conditions and it is anticipated that the reaction conditions could be optimised to favour the desired diol product. Ring contraction of acetonide-protected endoperoxide 23 by treatment with triphenylphosphine provi-
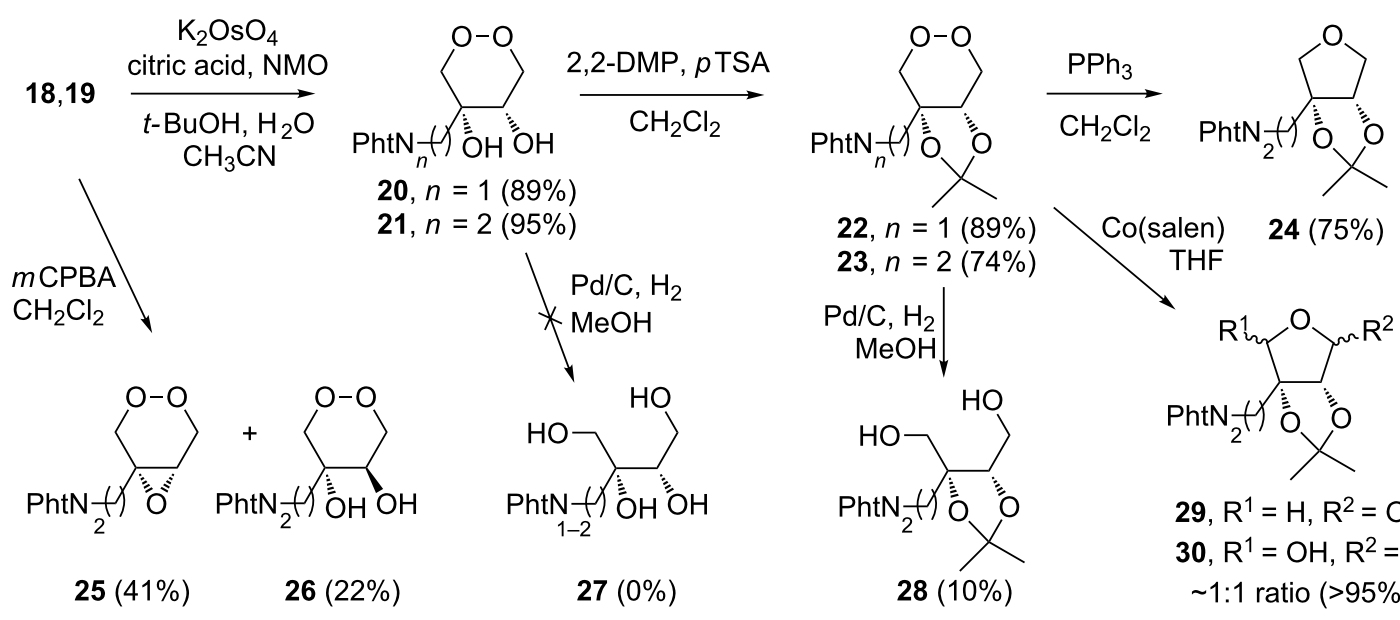

29, $\mathrm{R}^{1}=\mathrm{H}, \mathrm{R}^{2}=\mathrm{OH}$

30, $\mathrm{R}^{1}=\mathrm{OH}, \mathrm{R}^{2}=\mathrm{H}$

$\sim 1: 1$ ratio $(>95 \%)$

Scheme 4: Dihydroxylation and protection of endoperoxides 18 and 19 to provide novel building blocks 20-23 for azasugar synthesis. Preliminary exploration of the chemistry of endoperoxides 18-23 was encouraging and gave access to a variety of derivatives. 
ded ready access to tetrahydrofuran $\mathbf{2 4}$ in good yield [21]. Finally, treatment of endoperoxide $\mathbf{2 3}$ with Co(salen) gave ready access to the two lactol isomers $\mathbf{2 9 , 3 0}$ in quantitative yield ( $\approx 1: 1$ ratio of isomers) [10,22,23]. Lactol isomers $\mathbf{2 9 , 3 0}$ could potentially serve as precursors for the formation of substituted piperidines via reductive amination or be oxidised to yield lactones or lactam derivatives.

\section{Conclusion}

Herein, we report the development of a synthetic strategy using $[4+2]$-cycloaddition reactions to yield endoperoxides 18-23 that contain a protected primary amine. Such intermediates serve as useful new building blocks for organic synthesis. Preliminary exploration of the chemistry of these compounds was encouraging and gave access to a variety of novel protected azasugar precursors. We conclude that the choice of amine and dihydroxy protecting groups can have an impact on the success of the endoperoxide synthesis and its thermal stability, and that employing phthalimide and acetonide groups for $\mathrm{N}$ - and $O$-protection, respectively, allow for a range of chemical transformations to be carried out. We are in the process of optimising and exploring the chemistry of these building blocks and the results will be reported in due course.

\section{Supporting Information}

\section{Supporting Information File 1}

Experimental procedures for all compounds; ${ }^{1} \mathrm{H}$ and

${ }^{13} \mathrm{C}$ NMR spectra for novel compounds $\mathbf{1 3}, \mathbf{1 6}, \mathbf{1 8}-\mathbf{2 8}$.

[http://www.beilstein-journals.org/bjoc/content/ supplementary/1860-5397-13-63-S1.pdf]

\section{Acknowledgements}

The Lundbeck Foundation - Natural Sciences is gratefully acknowledged for financial support.

\section{References}

1. Winchester, B. G. Tetrahedron: Asymmetry 2009, 20, 645-651. doi:10.1016/j.tetasy.2009.02.048

2. Horne, G. In Carbohydrates as Drugs; Seeberger, P. H.; Rademacher, C., Eds.; Springer International Publishing: Cham, 2014; pp 23-51.

3. Horne, G.; Wilson, F. X.; Tinsley, J.; Williams, D. H.; Storer, R. Drug Discovery Today 2011, 16, 107-118. doi:10.1016/j.drudis.2010.08.017

4. Tamayo, J. A.; Franco, F.; Lo Re, D. Synlett 2010, 1323-1326. doi:10.1055/s-0029-1219827

5. Petakamsetty, R.; Jain, V. K.; Majhi, P. K.; Ramapanicker, R. Org. Biomol. Chem. 2015, 13, 8512-8523. doi:10.1039/C5OB01042J

6. Marjanovic, J.; Ferjancic, Z.; Saicic, R. N. Tetrahedron 2015, 71, 6784-6789. doi:10.1016/j.tet.2015.07.036
7. Karjalainen, O. K.; Koskinen, A. M. P. Org. Biomol. Chem. 2011, 9, 1231-1236. doi:10.1039/C0OB00747A

8. Compain, P.; Chagnault, V.; Martin, O. R. Tetrahedron: Asymmetry 2009, 20, 672-711. doi:10.1016/j.tetasy.2009.03.031

9. Avery, T. D.; Greatrex, B. W.; Sejer Pedersen, D.; Taylor, D. K.; Tiekink, E. R. T. J. Org. Chem. 2006, 73, 2633-2640. doi:10.1021/jo7024256

10. Pedersen, D. S.; Robinson, T. V.; Taylor, D. K.; Tiekink, E. R. T. J. Org. Chem. 2009, 74, 4400-4403. doi:10.1021/jo900392y

11. Robinson, T. V.; Taylor, D. K.; Tiekink, E. R. T. J. Org. Chem. 2006, 71, 7236-7244. doi:10.1021/jo060949p

12. Robinson, T. V.; Pedersen, D. S.; Taylor, D. K.; Tiekink, E. R. T. J. Org. Chem. 2009, 74, 5093-5096. doi:10.1021/jo900669u

13. James, T.; Simpson, I.; Grant, J. A.; Sridharan, V.; Nelson, A. Org. Lett. 2013, 15, 6094-6097. doi:10.1021/ol402988s

14. Pedersen, D. S.; Taylor, D. K.; Tiekink, E. R. T. Acta Crystallogr., Sect. E 2007, 63, o4301. doi:10.1107/S1600536807049252

15. Parikh, J. R.; Doering, W. v. E. J. Am. Chem. Soc. 1967, 89, 5505-5507. doi:10.1021/ja00997a067

16. Ley, S. V.; Norman, J.; Griffith, W. P.; Marsden, S. P. Synthesis 1994, 639-666. doi:10.1055/s-1994-25538

17. Dess, D. B.; Martin, J. C. J. Org. Chem. 1983, 48, 4155-4156. doi:10.1021/jo00170a070

18. Delfourne, E.; Kiss, R.; Le Corre, L.; Dujols, F.; Bastide, J.; Collignon, F.; Lesur, B.; Frydman, A.; Darro, F. J. Med. Chem. 2003, 46, 3536-3545. doi:10.1021/jm0308702

19. Xiao, X.; Antony, S.; Kohlhagen, G.; Pommier, Y.; Cushman, M. Bioorg. Med. Chem. 2004, 12, 5147-5160. doi:10.1016/j.bmc.2004.07.027

20. Erkkilä, A.; Pihko, P. M. J. Org. Chem. 2006, 71, 2538-2541. doi:10.1021/jo052529q

21. Greatrex, B. W.; Taylor, D. K. J. Org. Chem. 2004, 69, 2577-2579. doi:10.1021/jo030330c

22. Avery, T. D.; Haselgrove, T. D.; Taylor, D. K.; Tiekink, E. R. T.; Avery, T. D.; Rathbone, T. J. Chem. Commun. 1998, 333-334. doi:10.1039/A707360G

23. Avery, T. D.; Taylor, D. K.; Tiekink, E. R. T. J. Org. Chem. 2000, 65, 5531-5546. doi:10.1021/jo0002240

\section{License and Terms}

This is an Open Access article under the terms of the Creative Commons Attribution License (http://creativecommons.org/licenses/by/4.0), which permits unrestricted use, distribution, and reproduction in any medium, provided the original work is properly cited.

The license is subject to the Beilstein Journal of Organic Chemistry terms and conditions: (http://www.beilstein-journals.org/bjoc)

The definitive version of this article is the electronic one which can be found at: doi:10.3762/bjoc. 13.63 